\title{
A PCR-Based Method to Genotype Mice Knocked Out for All Four CD3 Subunits, the Standard Recipient Strain for Retrogenic TCR/CD3 Bone Marrow Reconstitution Technology
}

\author{
Alejandro Ferrer, Adam G. Schrum, and Diana Gil
}

\begin{abstract}
The novel T-cell receptor (TCR)/CD3-retrogenic-reconstitution system represents a very useful strategy for studying TCR/CD3 signaling. Two retroviral vectors containing genes for all six subunits of the TCR/CD3 complex are used to transduce bone marrow precursors and reconstitute lethally irradiated recipient mice. Mice used in this system as bone marrow donors lack all four $\mathrm{CD} 3$ subunits $\left(\mathrm{CD} 3 \gamma \delta \varepsilon \zeta^{-/-}\right)$. These mice are generated by crossing the strains $\mathrm{CD} 3 \zeta^{-/-}$and $\mathrm{CD} 3 \gamma \delta \varepsilon^{-/-}$, the latter resulting from a knockout construct targeted to $C D 3 \varepsilon$ that additionally silences the linked genes, $C D 3 \gamma$ and $C D 3 \delta$. Lacking mature T-cell function, $C D 3 \gamma \delta \varepsilon \zeta^{-/-}$mice are immunocompromised animals often produced by heterozygous breeding strategies on the C57BL/ 6 background. As a more rapid and reliable means to identify $\mathrm{CD} 3 \gamma \delta \varepsilon \zeta^{-}$- mice than previously described Northern and Southern blots, we designed polymerase chain reactions to distinguish knockout from wild-type $C D 3 \varepsilon$ and $C D 3 \zeta$ alleles, facilitating the identification of $\mathrm{CD} 3 \gamma \delta \varepsilon \zeta^{-/-}$mice.
\end{abstract}

Key words: DNA; genes; genetic testing; immunology; PCR

\section{Introduction}

$T^{1}$ HE T-CELL RECEPTOR (TCR), expressed in noncovalent association with the CD3 complex at the plasma membrane, is the receptor responsible for activating the adaptive immune functions of T cells. ${ }^{1}$ This receptor is composed of the clonotypic $\mathrm{TCR} \alpha \beta$ (or $\mathrm{TCR} \gamma \delta$ ) heterodimer that usually recognizes antigens in the form of peptides presented by the major histocompatibility complex. ${ }^{2}$ TCR antigen recognition activates the signal transduction cascade from the associated CD3 complex, ${ }^{3}$ which is composed of four invariant subunits: $\mathrm{CD} 3 \varepsilon, \mathrm{CD} 3 \gamma, \mathrm{CD} 3 \delta$, and $\mathrm{CD} 3 \zeta .{ }^{4}$ All subunits of the TCR/CD3 complex are synthesized in the endoplasmic reticulum of T cells, and expression of all of them is necessary for the receptor to be properly folded, assembled, and transported to the plasma membrane. ${ }^{5}$ Surface expression of the TCR/CD3 complex, including all four CD3 subunits, is essential for T-cell development. ${ }^{6-10}$ In CD $3 \gamma \delta \varepsilon^{-/-}$mice (originally named $\mathrm{CD} 3 \varepsilon^{\Delta \mathrm{P}}$ ), the insertion of the neomycin phosphotransferase cassette (neo-cassette) into the CD3\& locus on chromosome 9 was shown to also silence the expression of the linked genes $C D 3 \gamma$ and $C D 3 \delta .^{9,11,12}$ Crossing the $\operatorname{CD} 3 \gamma \delta \varepsilon^{-/-}$with
$\mathrm{CD} 3 \zeta^{-/-}$mice results in a strain deficient in all four CD3 subunits, CD $3 \gamma \delta \varepsilon \zeta^{-/-13}$ Deficiency of all CD3 subunits impedes T-cell development and results in mice that lack mature T cells. ${ }^{13}$

Bone marrow precursors from the $\mathrm{CD} 3 \gamma \delta \varepsilon \zeta^{-/-}$mice can be ideal to study the roles of TCR/CD3 proteins in the development and function of $\mathrm{T}$ cells, when retroviral transduction coupled with bone marrow reconstitution is employed to provide WT or mutant $C D 3$ transgenes. This principle was well illustrated in a series of work by Dr. Dario Vignali and colleagues, who used a multicistronic retroviral system to transduce CD $3 \gamma \delta \varepsilon \zeta^{-/-}$bone marrow with genes for all TCR/CD3 subunits, and used the transduced bone marrow to reconstitute lethally irradiated $\operatorname{CD} 3 \gamma \delta \varepsilon \zeta^{-/-}$mice. ${ }^{14-16}$ This launched the experimental use of TCR/CD3 retrogenic mice, a system that has gained significant popularity for its applicability to the study of T-cell signaling in primary immune responses.

Because $\mathrm{CD} 3 \gamma \delta \varepsilon \zeta^{-/}$mice lack peripheral $\mathrm{T}$ cells, their adaptive immune system is compromised. Consequently, production of these valuable mice through heterozygous breeding on a C57BL/6 (B6) background can be desirable to maintain the CD3 knockout $(\mathrm{KO})$ alleles present in healthy,

Department of Immunology, College of Medicine, Mayo Clinic, Rochester, Minnesota. 
Table 1. Sequence of Polymerase Chain Reaction Primers Used to Genotype

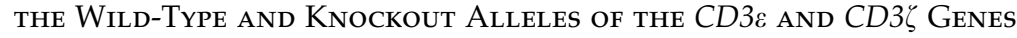

\begin{tabular}{|c|c|c|c|}
\hline Gene & Allele specificity & Sense & Sequence \\
\hline$C D 3 \varepsilon$ & $\begin{array}{l}\text { WT } \\
\text { WT } \\
\text { KO } \\
\text { KO }\end{array}$ & $\begin{array}{l}\text { Forward } \\
\text { Reverse } \\
\text { Forward } \\
\text { Reverse }\end{array}$ & $\begin{array}{l}\text { 5'-TGC AAG GTT CAC AGT CTT GC-3' } \\
\text { 5'-TTC CAC GAC AGA CAG AAC TC-3' } \\
\text { 5'-GGC AGT GAA AGG GAG AAA TC-3' } \\
\text { 5'-TCA TAG CCG AAT AGC CTC TC-3' }\end{array}$ \\
\hline$C D 3 \zeta$ & $\begin{array}{l}\text { WT } \\
\mathrm{KO} \\
\mathrm{WT}, \mathrm{KO}\end{array}$ & $\begin{array}{l}\text { Forward } \\
\text { Forward } \\
\text { Reverse }\end{array}$ & 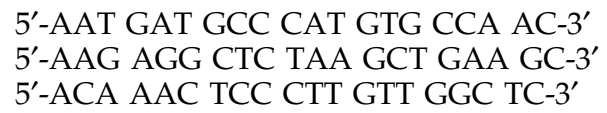 \\
\hline
\end{tabular}

$\mathrm{WT}$, wild type; $\mathrm{KO}$, knockout.

productive breeders. Because either one of the $C D 3 \varepsilon$ or $\mathrm{CD} 3 \zeta \mathrm{KO}$ alleles results in impaired assembly and surface expression of the remaining TCR/CD3 subunits, genotyping methods based on immunofluorescence staining of surface proteins by flow cytometry is not useful to distinguish $\mathrm{CD} 3 \gamma \delta \varepsilon \zeta^{-/}$mice from single knockouts. Currently, only Northern and Southern blot approaches have been published for use in genotyping mice from colonies carrying the $\mathrm{KO}$ alleles for these $C D 3 \varepsilon$ and $C D 3 \zeta$ genes. In an attempt to develop a more rapid and simple genotyping method to apply to the $\mathrm{CD} 3 \gamma \delta \varepsilon \zeta^{-/-}$mice and their parental strains, CD $3 \gamma \delta \varepsilon^{-/-}$ and $\mathrm{CD} 3 \zeta^{-1-}$, we have developed a new screening method based on polymerase chain reaction (PCR), a technique previously shown to be useful for screening mouse genomic DNA. ${ }^{17}$

\section{Materials and Methods}

\section{Mice}

B6 mice were purchased from The Jackson Laboratory (Bar Harbor, Maine). CD $3 \gamma \delta \varepsilon \zeta^{-/-}$mice on the B6 background were bred in a rodent barrier facility from homozygous pro- genitors that were kindly provided by Dr. Cox Terhorst (Beth Israel Deaconess Medical Center, Harvard Medical School, Boston, MA) and Dr. Dario Vignali (St. Jude Children's Research Hospital, Memphis, TN). CD $3 \gamma \delta \varepsilon \zeta^{-\prime-} \times \mathrm{B} 6(\mathrm{~F} 1)$ mice, double heterozygous for the WT and $\mathrm{KO}$ alleles of the $C D 3 \varepsilon$ and $C D 3 \zeta$ genes, were generated by crossing $\mathrm{CD} 3 \gamma \delta \varepsilon \zeta^{-/-}$mice with B6 mice in our animal facility. In addition, F2 offspring were generated by intercrossing F1 mice, and F3 offspring were generated by intercrossing F2 mice. Mouse procedures were approved by Mayo Institutional Animal Care and Use Committee and are consistent with National Institutes of Health guidelines for the care and use of animals.

\section{Design of PCR primers}

For the $C D 3 \varepsilon$ gene, pairs of forward and reverse primers were designed to specifically amplify either the wild-type (WT) WT or the KO allele in separate PCR amplifications (Table 1). Primers annealing with the CD3\& WT allele were located inside the sequence that in the $\mathrm{KO}$ allele was replaced by the neo-cassette (Fig. 1). For the pair of primers directed against the $C D 3 \varepsilon \mathrm{KO}$ allele, the forward primer was designed to anneal in the $C D 3 \varepsilon$ gene upstream of the inserted neo-

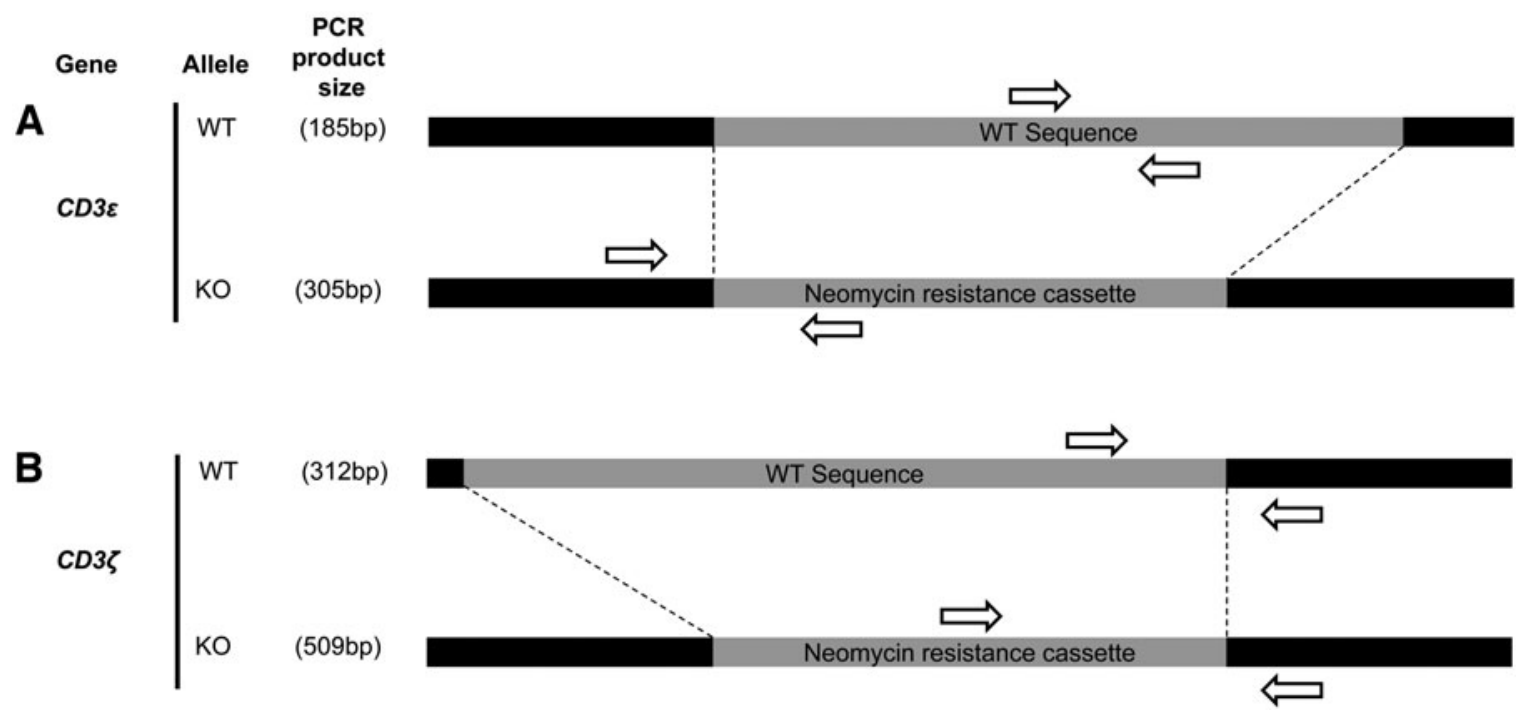

FIG. 1. Location of the primers used to genotype the wild-type (WT) and knockout $(\mathrm{KO})$ alleles of the $C D 3 \varepsilon$ and $C D 3 \zeta$ genes. Schematic map showing the location of the forward (right pointing arrows) and reverse (left pointing arrows) primers

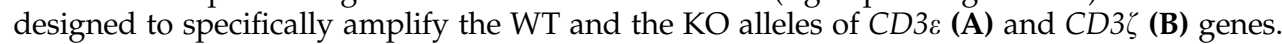


cassette, whereas the reverse primer annealed in the $5^{\prime}$ region within the neo-cassette (Fig. 1). For the CD3 $\zeta$ gene, a common reverse primer annealing with both $\mathrm{WT}$ and $\mathrm{KO}$ alleles was designed to be located downstream of the neo-cassette insertion point (Fig. 1). This primer was paired with a forward primer specific for either the $C D 3 \zeta \mathrm{WT}$ or the $C D 3 \zeta \mathrm{KO}$ allele. The forward primer specific for the CD3 $\zeta$ WT allele was designed to anneal in the $3^{\prime}$ region of the genomic DNA sequence substituted by the neo-cassette in the $\mathrm{CD} 3 \zeta^{-/-}$ mouse (Fig. 1). The forward primer specific for the $C D 3 \zeta$ $\mathrm{KO}$ allele was located in the $3^{\prime}$ region of the neo-cassette (Fig. 1). Using these three $C D 3 \zeta$ primers in a single reaction to amplify both alleles in the F1 mice led to variable results (data not shown) possibly caused by competition of both forward primers for the reverse primer. To solve this problem, two PCR amplifications were performed separately, one to screen the WT allele, and one to screen the $\mathrm{KO}$ allele of the $C D 3 \zeta$ gene. In order to ensure that these sets of primers would be compatible with the screening of mice that may carry $\mathrm{KO}$ alleles for both $C D 3 \varepsilon$ and $C D 3 \zeta$ genes, we prevented the neo-cassette inserted in the $\mathrm{KO}$ allele of one $C D 3$ gene from interfering with the PCR of the other CD3 $\mathrm{KO}$ allele by designing the primers for $\mathrm{CD} 3 \varepsilon \mathrm{KO}$ allele to anneal in the $5^{\prime}$ region of the neo-cassette and those for the $C D 3 \zeta \mathrm{KO}$ allele to anneal to the $3^{\prime}$ region (Fig. 1).

\section{Preparation of genomic DNA as PCR template}

Genomic DNA was isolated from mouse-tail tissue using the commercial kit DNeasy ${ }^{\circledR}$ Blood \& Tissue (Qiagen) following the protocol provided by the manufacturer. Tail tissue was cut into small pieces and incubated overnight at $56^{\circ} \mathrm{C}$ in lysis buffer supplemented with proteinase $\mathrm{K}$ (both included in the kit). The next day, $200 \mu \mathrm{L}$ of AL buffer (included in the kit) mixed with $200 \mu \mathrm{L}$ of ethanol was added to the samples and strongly shaken in a Vortex Gene 2 (Scientific Industries). The mixture was transferred to a DNeasy Mini Spin column (provided with the kit) and centrifuged for $1 \mathrm{~min}$ at $6000 \mathrm{~g}$. Flow-through was discarded, and $500 \mu \mathrm{L}$ of AW1 buffer (included in the kit) was added to the column and spun using the same conditions. Flow-through was discarded again. Five hundred microliters of buffer AW2 (included with the kit) was added to the column and centrifuged at 20,000 $\mathrm{g}$ for $3 \mathrm{~min}$. The column was incubated for $1 \mathrm{~min}$ with $100 \mu \mathrm{L}$ of DNAse free water (Promega). A final centrifugation for $1 \mathrm{~min}$ at $6000 \mathrm{~g}$ was performed. Concentration of total DNA was measured in a Nanodrop ND-1000 Spectrophotometer (Thermo Scientific).

\section{PCR Methods}

Primers were synthesized by Integrated DNA Technologies. Stock vials of primers described above were resuspended to a final concentration of $100 \mu \mathrm{M}$ in DNAse free water and diluted 1:10 to make working solutions prior to being employed in the PCR amplifications. For each CD3 gene tested, two PCR amplifications per mouse were set: one specific to detect the WT allele, and another one for the $\mathrm{KO}$ allele. Each PCR amplification was prepared by mixing $12.5 \mu \mathrm{L}$ of GoTaq ${ }^{\circledR}$ Green Master Mix (Promega), $2.5 \mu \mathrm{L}$ of each of the corresponding primer, and $100 \mathrm{ng}$ of genomic DNA to function as the PCR template. A final volume of $25 \mu \mathrm{L}$ was achieved using DNAse free water (Promega). A negative control using all reagents except template DNA was also included. Reactions were carried out in a T3000 thermocycler (Biometra) using the following cycling conditions: $2 \mathrm{~min}$ at $95^{\circ} \mathrm{C}$ followed by 40 cycles of $95^{\circ} \mathrm{C}$ for $30 \mathrm{sec}, 55^{\circ} \mathrm{C}$ (for $\mathrm{CD} 3 \varepsilon$ gene) or $53^{\circ} \mathrm{C}$ (for $\mathrm{CD} 3 \zeta$ gene) for $1 \mathrm{~min}$, and $72^{\circ} \mathrm{C}$ for $1 \mathrm{~min}$. A final extension step at $72^{\circ} \mathrm{C}$ for $5 \mathrm{~min}$ was performed after the cycles. After this step, samples were kept at $4^{\circ} \mathrm{C}$ until being electrophoresed in $2 \%$ agarose $1 \times$ TAE (Tris [ $40 \mathrm{mM}$ Tris], acetic acid [20 mM] and ethylendiaminetetraacetic acid [1 mM]) gels. For visualization of electrophoresed PCR products, gels were stained with $1 \times$ SYBR ${ }^{\circledR}$ Safe DNA Gel Stain (Life Technologies) and digital images were captured in a Gel Doc XR + system (Bio-Rad).

\section{Statistical analysis}

Chi-squared test was used to compare F3 genotype frequencies with the Mendelian frequencies that would be expected based on the genotype of the F2 parents.

\section{Results and Discussion}

We designed specific PCR primers to amplify either the WT or $\mathrm{KO}$ alleles of $C D 3 \varepsilon$ and $C D 3 \zeta$ genes from genomic DNA templates (see Methods; Fig. 1). Genomic DNA was extracted from tail tissue from the following mice: (i) B6 $\mathrm{WT}$, (ii) $\mathrm{CD} 3 \gamma \delta \varepsilon \zeta^{-/-}$, and (iii) $\mathrm{CD} 3 \gamma \delta \varepsilon \zeta^{-/-} \times \mathrm{B} 6 \mathrm{~F} 1$ (F1) mice (double heterozygous for the CD3 $\varepsilon$ and $C D 3 \zeta \mathrm{WT}$ and $\mathrm{KO}$ alleles). The resulting DNA samples were used as templates of known genotype to test the amplification of the WT and $\mathrm{KO}$ alleles by PCR for both $C D 3 \varepsilon$ and $C D 3 \zeta$ genes. During the optimization of the PCR amplifications, slight changes in the annealing temperature of the primers specific for the different $C D 3 \varepsilon$ and $C D 3 \zeta$ alleles being tested compromised either the specificity or the annealing of the primers (data not shown). We established $55^{\circ} \mathrm{C}$ as the optimal annealing temperature for the primers specific for the $C D 3 \varepsilon$ alleles, while $53^{\circ} \mathrm{C}$ was optimal for the $C D 3 \zeta$ primers (Table 1 ). PCR products were visualized following electrophoresis in $2 \%$ agarose gels. As expected from our primer design described in Figure 1, WT and $\mathrm{KO}$ alleles for the $C D 3 \varepsilon$ and $C D 3 \zeta$ genes generated PCR products of distinguishable size (data not shown). Therefore, we combined the PCR products from the amplification of the WT and $\mathrm{KO}$ alleles for each CD3 gene and electrophoresed them together in one single lane. As shown in Figure 2, the mixed PCR samples generated unique, clearly distinguishable, band patterns on the gels for each CD3 gene and the expected genotypes (homozygous WT, heterozygous [Het], homozygous $\mathrm{KO}$ ).

Breeding experiments were undertaken to examine the inheritance patterns associated with the PCR products marking the WT and $\mathrm{KO}$ alleles. First, F2 offspring resulting from intercrossed $\mathrm{F} 1$ mice $\left(\mathrm{CD} 3 \gamma \delta \varepsilon \zeta^{-/-} \times \mathrm{B} 6\right)$ were genotyped for $\mathrm{CD} 3 \varepsilon$ and $C D 3 \zeta$ genes by PCR. Next, five breeding pairs were arranged that consisted of F2 parents with heterogeneous genotypes for both genes. Finally, the F3 offspring resulting from these breeding pairs were genotyped by PCR (Table 2). The PCR results were subjected to chi-square testing, which showed that the genotypes for both CD3 genes found by PCR followed the expected Mendelian distributions (Table 2). As anticipated from the extensive work with this cassette reported in the literature, ${ }^{18,19}$ these results indicate that the 

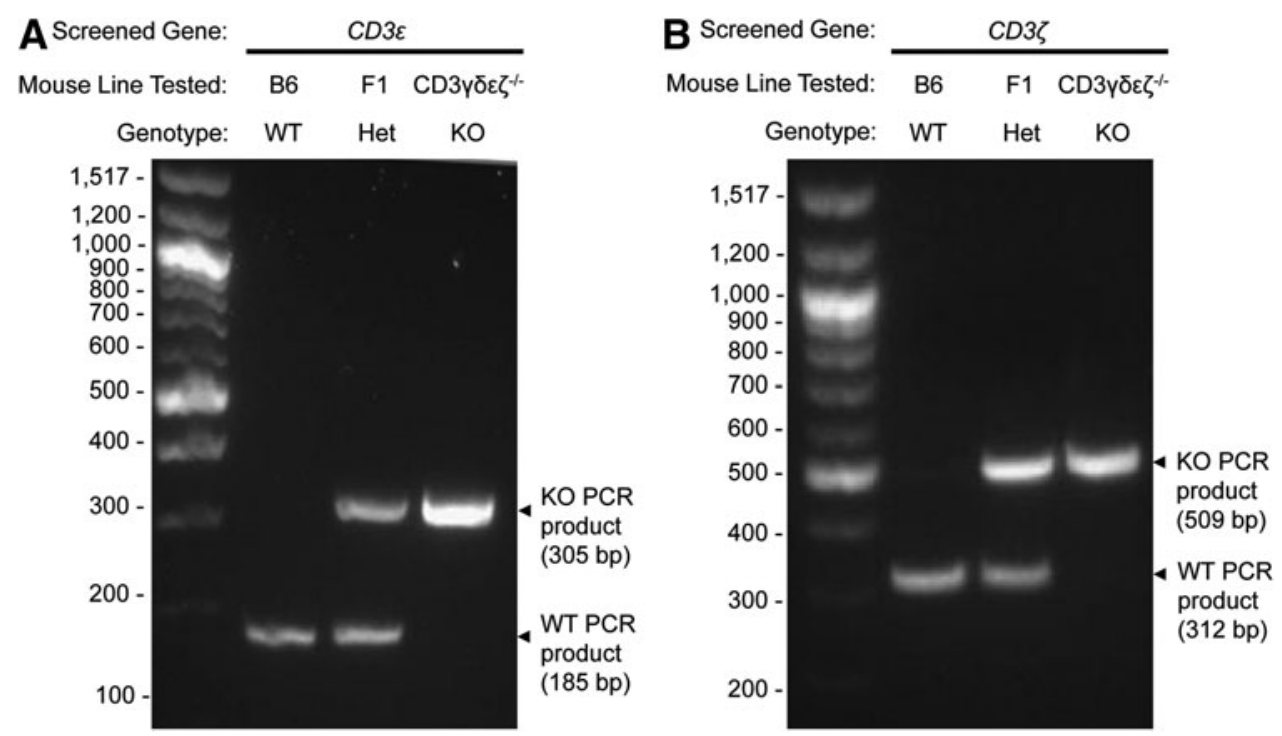

FIG. 2. WT and $\mathrm{KO}$ alleles of the $C D 3 \varepsilon$ and $C D 3 \zeta$ genes can be distinguished by PCR. Genomic DNA samples from the mouse strains $\mathrm{B} 6, \mathrm{CD} 3 \gamma \delta \varepsilon \zeta^{-/-}$, and their $\mathrm{F} 1$ cross $\left(\mathrm{B} 6 \times \mathrm{CD} 3 \gamma \delta \varepsilon \zeta^{-/-}\right)$were tested by PCR for the amplification of either the WT or $\mathrm{KO}$ alleles of the $C D 3 \varepsilon$ (A) and $C D 3 \zeta$ (B) genes. For each CD3 gene and mouse strain tested, the PCR amplifications of the WT and $\mathrm{KO}$ alleles were mixed and loaded together in $2 \%$ agarose gels. Arrowheads indicate the size of the PCR products found in the gels. As expected according to each genotype, B6 and CD $3 \gamma \delta \varepsilon \zeta^{-/-}$mice generated single PCR products from the either the WT or the KO alleles, respectively, while F1 mice displayed heterozygosity (Het) by generating the PCR products for both alleles.

neo-cassette is stably inserted in the genome of these mice, allowing access by PCR as a reliable method for genotyping.

To conclude, we have designed a rapid and robust PCRbased method for identifying $\operatorname{CD} 3 \gamma \delta \varepsilon \zeta^{-/-}$mice. These mice represent a critical component of studies that incorpo- rate the use of the TCR/CD3 retrogenic bone marrow reconstitution system. The clear and simple screening technique presented here is predicted to facilitate identification of these mice in breeding colonies, and the use of these mice in experiments.

Table 2. Polymerase Chain Reaction-Based Genotyping of CD3 Alleles Confirms Mendelian Inheritance of the Wild-Type and Knockout Genes

\begin{tabular}{|c|c|c|c|c|c|c|c|c|c|}
\hline & & & \multicolumn{6}{|c|}{ No. of F3 mice/genotype } & \\
\hline & \multicolumn{2}{|c|}{ F2 breeding pair } & \multicolumn{3}{|c|}{ Expected Mendelian distribution } & \multicolumn{3}{|c|}{ Observed by PCR } & \\
\hline & Parent 1 & Parent 2 & $W T$ & $H T$ & KO & WT & $H T$ & $\mathrm{KO}$ & \\
\hline \multicolumn{10}{|c|}{ PCR CD3 $\varepsilon$ genotype } \\
\hline 1 & HT & HT & 1.5 & 3 & 1.5 & 3 & 1 & 2 & \\
\hline 2 & $\mathrm{HT}$ & WT & 3.5 & 3.5 & 0 & 4 & 3 & 0 & \\
\hline 3 & $\mathrm{HT}$ & $\mathrm{KO}$ & 0 & 2 & 2 & 0 & 1 & 3 & \\
\hline 4 & HT & HT & 1.25 & 2.5 & 1.25 & 2 & 2 & 1 & \\
\hline 5 & $\mathrm{HT}$ & WT & 3.5 & 3.5 & 0 & 3 & 4 & 0 & \\
\hline \multicolumn{3}{|c|}{ Total number of mice } & 9.75 & 14.5 & 4.75 & 12 & 11 & 6 & $p=0.4289$ \\
\hline \multicolumn{10}{|c|}{ PCR CD3 $\zeta$ genotype } \\
\hline 1 & $\mathrm{HT}$ & $\mathrm{KO}$ & 0 & 3 & 3 & 0 & 4 & 2 & \\
\hline 2 & HT & $\mathrm{KO}$ & 0 & 3.5 & 3.5 & 0 & 4 & 3 & \\
\hline 3 & HT & $\mathrm{KO}$ & 0 & 2 & 2 & 0 & 1 & 3 & \\
\hline 4 & $\mathrm{KO}$ & WT & 0 & 5 & 0 & 0 & 5 & 0 & \\
\hline 5 & HT & HT & 1.75 & 3.5 & 1.75 & 1 & 3 & 3 & \\
\hline \multicolumn{3}{|c|}{ Total number of mice } & 1.75 & 17 & 10.25 & 1 & 17 & 11 & $p=0.8285$ \\
\hline
\end{tabular}

$\mathrm{F} 2$ offspring resulting from intercrossed $\mathrm{F} 1$ mice $\left(\mathrm{CD} 3 \gamma \delta \varepsilon \zeta^{-1-} \times \mathrm{B} 6\right)$ were genotyped for $\mathrm{CD} 3 \varepsilon$ and $C D 3 \zeta$ genes by PCR. Subsequently, five breeding pairs were arranged that consisted of F2 parents with heterogeneous genotypes for both genes. The table summarizes the PCR genotypes of the F2 parents, and the numbers of expected versus PCR-observed genotypes among the F3 offspring. The chi-square test showed that the numbers of F3 mice found by PCR for each possible CD3E and CD3 $\zeta$ genotype were not significantly different from their expected frequencies based on a Mendelian distribution of the $C D 3 \varepsilon$ and $C D 3 \zeta \mathrm{WT}$ and $\mathrm{KO}$ alleles $(p>0.05)$.

$\mathrm{PCR}$, polymerase chain reaction; HT, heterozygote. 


\section{Acknowledgments}

This work was supported by Mayo Foundation (A.F., A.G.S., D.G.) and National Institutes of Health Grant 1R56AI097187-01 (D.G.). We thank Drs. Cox Terhorst (Beth Israel Deaconess Medical Center, Harvard Medical School, Boston, MA) and Dario Vignali (St. Jude Children's Research Hospital, Memphis, TN) for generously providing us with $\mathrm{CD} 3 \gamma \delta \varepsilon \zeta^{-/-}$mice. We also thank our colleagues at the Mayo Clinic: Robert Stiles and Michael Bell for excellent technical support, and Michele Hoffmann for editing the manuscript.

\section{Author Disclosure Statement}

No competing financial interest exists.

\section{References}

1. Smith-Garvin JE, Koretzky GA, Jordan MS. T cell activation. Annu Rev Immunol. 2009;27:591-619.

2. Huang J, Meyer C, Zhu C. T cell antigen recognition at the cell membrane. Mol Immunol. 2012;52:155-164.

3. Werlen G, Palmer E. The T-cell receptor signalosome: a dynamic structure with expanding complexity. Curr Opin Immunol. 2002;14:299-305.

4. Alarcon B, Gil D, Delgado P, et al. Initiation of TCR signaling: regulation within CD3 dimers. Immunol Rev. 2003;191: 38-46.

5. Call ME, Wucherpfennig KW. Molecular mechanisms for the assembly of the T cell receptor-CD3 complex. Mol Immunol. 2004;40:1295-1305.

6. Dave VP. Hierarchical role of CD3 chains in thymocyte development. Immunol Rev. 2009;232:22-33.

7. Dave VP, Cao Z, Browne C, et al. CD3 delta deficiency arrests development of the alpha beta but not the gamma delta $T$ cell lineage. EMBO J. 1997;16:1360-1370.

8. Liu CP, Ueda R, She J, et al. Abnormal T cell development in CD3-zeta-/- mutant mice and identification of a novel T cell population in the intestine. EMBO J. 1993;12:4863-4875.

9. Wang N, Wang B, Salio M, et al. Expression of a CD3 epsilon transgene in CD3 epsilon(null) mice does not restore CD3 gamma and delta expression but efficiently rescues $\mathrm{T}$ cell de- velopment from a subpopulation of prothymocytes. Int Immunol. 1998;10:1777-1788.

10. Love PE, Shores EW, Johnson MD, et al. T cell development in mice that lack the zeta chain of the $\mathrm{T}$ cell antigen receptor complex. Science. 1993;261:918-921.

11. Gold DP, van Dongen JJ, Morton CC, et al. The gene encoding the epsilon subunit of the $\mathrm{T} 3 / \mathrm{T}$-cell receptor complex maps to chromosome 11 in humans and to chromosome 9 in mice. Proc Natl Acad Sci U S A. 1987;84:1664-1668.

12. Pham CT, MacIvor DM, Hug BA, et al. Long-range disruption of gene expression by a selectable marker cassette. Proc Natl Acad Sci U S A. 1996;93:13090-13095.

13. Wang B, Wang N, Whitehurst CE, et al. T lymphocyte development in the absence of CD3 epsilon or CD3 gamma delta epsilon zeta. J Immunol. 1999;162:88-94.

14. Holst J, Szymczak-Workman AL, Vignali KM, et al. Generation of T-cell receptor retrogenic mice. Nat Protoc. 2006;1:406-417.

15. Holst J, Wang H, Eder KD, et al. Scalable signaling mediated by $\mathrm{T}$ cell antigen receptor-CD3 ITAMs ensures effective negative selection and prevents autoimmunity. Nat Immunol. 2008;9:658-666.

16. Szymczak AL, Vignali DA. Development of 2A peptidebased strategies in the design of multicistronic vectors. Expert Opin Biol Ther. 2005;5:627-638.

17. Chen SZ, Evans GA. A simple screening method for transgenic mice using the polymerase chain reaction. Biotechniques. 1990;8:32-33.

18. Southern PJ, Berg P. Transformation of mammalian cells to antibiotic resistance with a bacterial gene under control of the SV40 early region promoter. J Mol Appl Genet. 1982;1:327-341.

19. Kaur G, Gulati N, Mandal A, et al. Expression and stable germline transmission of neomycin-resistance gene in transgenic mice. Indian J Exp Biol. 1998;36:1209-1215.

Address correspondence to: Diana Gil, PhD

Department of Immunology College of Medicine, Mayo Clinic 200 1st St. SW, 321 Guggenheim Bldg. Rochester, MN 55905

E-mail: gilpages.diana@mayo.edu 